
NPK Dan Bokashi. Journal Viabel Pertanian. (2020), 14(1)37-43

\title{
RESPON PERTUMBUHAN DAN HASIL TANAMAN CABAI MERAH KERITING (Capsicum annum Var. Longun L.) TERHADAP PEMBERIAN DOSIS PUPUK NPK DAN BOKASHI
}

\author{
${ }^{1)}$ Faiftin Nurul Laili ${ }^{2)}$ Tri Kurniastuti ${ }^{3)}$ Palupi Puspitorini \\ ${ }^{1)}$ Mahasiswa Fakultas Pertanian, Universitas Islam Balitar \\ ${ }^{2,3)}$ Dosen Fakultas Pertanian, Universitas Islam Balitar \\ Email : ${ }^{1)}$ faiftinferafory@gmail.com ${ }^{2)}$ kurniastuti5@gmail.com \\ ${ }^{3)}$ puspitorini.palupi@gmail.com
}

\begin{abstract}
The aims of this study was 1) to determine the effect of interactions between the dose of NPK fertilizer and bokashi fertilizer on growth and yield of curly red chilli plants 2 ) to determine the effect of NPK fertilizer dose on the growth and yield of curly red chili plants 3) to determine the effect of bokashi fertilizer dose on the growth and yield of curly red chilli plants. This study was arranged using a factorial randomized block design (RAK), factor I was NPK fertilizer namely N1: 0.624 gram, N2: 0.832 gram, N3: 1.04 gram, N4 1,248 gram, factor II is fertilizer Bokashi is B1: 20.8 grams, B2: 41.6 grams, B3: 49.9 grams, B4: 62.4 grams. There were 16 treatments and repeated 3 times, so there were 48 experimental units. Data were analyzed by analysis of variance method based on (ANNOVA) level of 5\% analysis of variance analysis. If the treatment has a significant effect on the observed variables then continued with the Duncan test of the level of $5 \%$. The results of variance showed that there was a significant interaction with NPK fertilizer treatment $(\mathrm{N})$ and Bokashi fertilizer (B) on plant height, stem diameter, number of leaves, anditotal number of fruit plantations at 14, 21, 28, 35, and 49 DAP (date after plant). The best treatment wasifound in the dosage of 0.832 gram NPK fertilizer and 41.6 gram Bokashi fertilizer (N2B2).
\end{abstract}

Keywords: curly red chili, bokashi fertilizer, NPK fertilizer, yield, growth

\section{PENDAHULUAN}

Cabai merah keriting (Capsicum annum Var. Longun L.) merupakan tanaman yang digolongkan ke dalam anggota genus Capsicum. Bagian yang digunakan dari tanaman cabai yaitu buahnya sebagai sayuran dan bumbu sebagai penguat rasa makanan terutama sebagai bahan rasa pedas seperti sambal. Cabai termasuk tanaman semusim yang berdiri tegak, berbentuk perdu, dan menjadi salah satu komoditas sayuran yang banyak dibudidayakan, dan menjadi komoditas yang popular di dunia (Waskito et al. 2018).

Upaya untuk meningkatkan produksi tanaman cabai dengan cara mengolah lahan secara tepat agar kesuburan tanah tetap terjaga. Untuk mendapatkan pertumbuhan yang optimal perlu dilakukannya pemeliharaan tanaman salah satunya adalah pemupukan (Hapsoh et al. 2017). Pupuk ialah bahan yang diberikan ke dalam tanah baik yang organic maupun anorganik guna mencukupi kebutuhan hara yang diperlukan tanaman. Unsur hara yang menentukan produktivitas dan kualitas buah cabai diantaranya unsur $\mathrm{N}, \mathrm{P}$, dan $\mathrm{K}$. Menurut Muchyar (2005) pemberian pupuk N, P dan K dapat meningkatkan hasil dan ukuran buah cabai. Pupuk organic yang dapat digunakan yaitu bokashi. Bokashi merupakan bahan organik yang telah difermentasi yang dapat memperbaiki kualitas tanah, sifat fisik, kimia dan biologi tanah (Musnamar, E. I. 2003).

Kombinasi bokashi sampah organic rumah tangga dan dosis NPK berpengaruh nyata terhadap pertumbuhan (pertambahan tinggi, jumlah buku cabang, umur muncul 

NPK Dan Bokashi. Journal Viabel Pertanian. (2020), 14(1)37-43

bunga pertama, dan biomasa tanaman) dan produksi (jumlah buah dan berat segar buah pertanaman). Dalam penelitian ini pemberian bokashi sampah organik rumah tangga dapat mengurangi penggunaan NPK sebesar 25\%. Hal ini dikarenakan bahwa pada pemberian 75\% NPK yang dikombinasikan dengan 10 ton/ha-1 bokashi sampah organik rumah tangga dapat memberikan hasil terbaik pada produksi tanaman cabe rawit (Silvia et al. 2016).

\section{Rancangan Penelitian}

\section{METODOLOGI}

Penelitian ini menggunakan Rancangan Acak Kelompok (RAK) disusun secara faktorial terdiri dari dua factor yaitu faktor 1 dosis pupuk anorganik NPK Phonska (N) yang terdiri dari 4 level, yaitu ; N1 : 60\% dosis pupuk NPK Phonska $150 \mathrm{~kg} / \mathrm{Ha}$ atau 0.624 gram/polybag, N2 : $80 \%$ dosis pupuk NPK phonska $200 \mathrm{~kg} / \mathrm{Ha}$ atau 0.832 gram/polybag, N3 : 100\% dosis pupuk NPK Phonska $250 \mathrm{~kg} / \mathrm{Ha}$ atau 1.04 gram/polybag, N4: $120 \%$ dosis pupuk NPK phonska $300 \mathrm{~kg} / \mathrm{Ha}$ atau 1.248 gram/polybag. Sedangkan faktor 2 pupuk organik bokashi (B) yang terdiri dari 3 level, yaitu ; B1: dosis pupuk organik bokhasi ( 5 ton/h) $20.8 \mathrm{gram} /$ polybag, B2:, Dosis pupuk Organik Bokashi (10 ton/h) $41.6 \mathrm{gram} /$ polybag. B3: Dosis pupuk Organik Bokashi (15 ton/h) $62.4 \mathrm{gram} /$ polybag. Sehingga menghasilkan 12 kombinasi perlakuan.

Analisis data menggunakan analisis ragam (uji F) pada taraf 5\%. Bila hasil pengujian diperoleh perbedaaan yang nyata antar perlakuan maka dilanjutkan dengan uji perbandingan antar perlakuan dengan menggunakan uji DMRT Duncan pada taraf $5 \%$. Variabel pengamatan dalam penelitian ini yaitu : tinggi tanaman, jumlah daun, diameter batang, jumlah buah total, bobot buah total.

\section{Tinggi Tanaman}

\section{HASIL PENELITIAN}

Berdasarkan hasil analisis dari sidik ragam (ANOVA) pada taraf 5\% menunjukkan bahwa terdapat interaksi yang nyata terhadap tinggi tanaman cabai merah keriting (Capsicum annum Var. Longun L.) pada umur pengamatan 14 HST, 21 HST, 28 HST, 35 HST,42 HST. Untuk mengetahui perbedaan antara perlakuan yang terbaik terhadap tinggi tanaman dapat di lihat pada tabel di bawah ini :

Tabel 1. Rata-Rata Tinggi Tanaman Cabai Merah Keriting Pada Umur Pengamatan 14 HST, 21 HST, 28 HST, 35 HST, 42 HST.

\begin{tabular}{llllll}
\hline \multirow{2}{*}{ Perlakuan } & \multicolumn{5}{c}{ Tinggi Tanaman $(\mathrm{cm})$} \\
& $14 \mathrm{HST}$ & $21 \mathrm{HST}$ & $28 \mathrm{HST}$ & $35 \mathrm{HST}$ & $42 \mathrm{HST}$ \\
\hline N1B1 & $13.23 \mathrm{a}$ & $24.88 \mathrm{a}$ & $30.26 \mathrm{a}$ & $45.94 \mathrm{a}$ & $61.27 \mathrm{a}$ \\
N2B1 & $14.25 \mathrm{~b}$ & $25.32 \mathrm{ab}$ & $35.12 \mathrm{~b}$ & $48.67 \mathrm{ab}$ & $64.79 \mathrm{ab}$ \\
N3B1 & $14.23 \mathrm{~b}$ & $25.88 \mathrm{ab}$ & $35.29 \mathrm{~b}$ & $48.81 \mathrm{ab}$ & $64.82 \mathrm{ab}$ \\
N4B1 & $15.00 \mathrm{~d}$ & $27.06 \mathrm{~b}$ & $35.89 \mathrm{~b}$ & $50.93 \mathrm{~b}$ & $66.00 \mathrm{~b}$ \\
N1B2 & $14.39 \mathrm{bc}$ & $26.07 \mathrm{ab}$ & $35.56 \mathrm{~b}$ & $50.14 \mathrm{~b}$ & $64.62 \mathrm{ab}$ \\
N2B2 & $15.24 \mathrm{~d}$ & $29.09 \mathrm{c}$ & $39.88 \mathrm{c}$ & $55.86 \mathrm{c}$ & $68.18 \mathrm{~b}$ \\
N3B2 & $14.29 \mathrm{~b}$ & $26.46 \mathrm{ab}$ & $36.23 \mathrm{~b}$ & $50.42 \mathrm{~b}$ & $65.14 \mathrm{ab}$ \\
N4B2 & $14.28 \mathrm{~b}$ & $26.24 \mathrm{ab}$ & $35.39 \mathrm{~b}$ & $48.95 \mathrm{ab}$ & $62.93 \mathrm{ab}$ \\
N1B3 & $14.58 \mathrm{bc}$ & $26.82 \mathrm{~b}$ & $35.73 \mathrm{~b}$ & $52.83 \mathrm{bc}$ & $66.50 \mathrm{ab}$ \\
N2B3 & $14.58 \mathrm{bc}$ & $27.05 \mathrm{~b}$ & $35.95 \mathrm{~b}$ & $49.74 \mathrm{ab}$ & $64.18 \mathrm{ab}$ \\
N3B3 & $14.74 \mathrm{c}$ & $26.51 \mathrm{ab}$ & $35.18 \mathrm{~b}$ & $49.55 \mathrm{ab}$ & $64.08 \mathrm{ab}$ \\
N4B3 & $14.38 \mathrm{bc}$ & $26.59 \mathrm{ab}$ & $35.76 \mathrm{~b}$ & $51.64 \mathrm{~b}$ & $63.25 \mathrm{ab}$ \\
\hline
\end{tabular}

Keterangan : Angka-angka yang diikuti dengan huruf yang sama pada kolom yang sama tidak berbeda nyata pada uji Duncan $(\alpha=0,05)$. 

NPK Dan Bokashi. Journal Viabel Pertanian. (2020), 14(1)37-43

Hasil tertinggi terhadap tinggi tanaman cabai merah keriting ditunjukkan pada perlakuan dosis NPK Phonska $0.832 \mathrm{~g} /$ polybag dan Bokashi $41.6 \mathrm{~g} /$ polybag (N2B2) pada semua umur pengamatan dan perlakuan terendah ditunjukkan perlakuan dosis NPK Phonska $0.624 \mathrm{~g} /$ polybag dan Bokashi $20.8 \mathrm{~g} /$ polybag (N1B1) pada semua umur pengamatan. Hal ini di duga NPK dan Bokashi mempunyai peranan yang baik dalam meningkatkan laju pertumbuhan tanaman. Interaksi perlakuan ini saling melengkapi dalam meningkatakan laju pertumbuhan tanaman. Pemberian unsur NPK dan bokashi cukup tersedia dan baik peranannya dalam asupan unsur hara tanaman cabai merah keriting. Sehingga tanaman mampu menyerap semua unsur hara yang tersedia sesuai dengan kebutuhan. Pemupukan NPK dapat meningkatkan pertumbuhan terutama tinggi tanaman, diduga karena peranan dari masing-masing unsur hara $\mathrm{N}, \mathrm{P}$, dan $\mathrm{K}$ yang dapat merangsang pertumbuhan vegetatif tanaman (Hulopi 2006).

\section{Jumlah Daun}

Berdasarkan hasil analisis sidik ragam (ANOVA) pada taraf 5\% terdapat interaksi yang nyata terhadap jumlah daun tanaman cabai merah keriting (Capsicum annum Var. Longun L.) pada umur pengamatan 14 HST, 21 HST, 28 HST, 35 HST, 42 HST.Untuk mengetahui perbedaan antara perlakuan yang terbaik terhadap tinggi tanaman dapat di lihat pada tabel di bawah ini :

Tabel 2. Rata-Rata Jumlah Daun Cabai Merah Keriting Pada Umur Pengamatan 14 HST, 21 HST, 28 HST, 35 HST, 42 HST.

\begin{tabular}{llllll}
\hline \multirow{2}{*}{ Perlakuan } & & \multicolumn{5}{c}{ Jumlah Daun $(\mathrm{cm})$} \\
& $14 \mathrm{HST}$ & $21 \mathrm{HST}$ & $35 \mathrm{HST}$ & $49 \mathrm{HST}$ & $63 \mathrm{HST}$ \\
\hline N1B1 & $6.44 \mathrm{a}$ & $12.00 \mathrm{a}$ & $16.22 \mathrm{a}$ & $48.44 \mathrm{a}$ & $72.00 \mathrm{a}$ \\
N2B1 & $7.10 \mathrm{~b}$ & $12.77 \mathrm{bc}$ & $17.77 \mathrm{~b}$ & $50.99 \mathrm{~b}$ & $74.11 \mathrm{~b}$ \\
N3B1 & $7.11 \mathrm{~b}$ & $12.22 \mathrm{ab}$ & $17.88 \mathrm{~b}$ & $50.44 \mathrm{~b}$ & $74.33 \mathrm{~b}$ \\
N4B1 & $7.44 \mathrm{~b}$ & $13.11 \mathrm{c}$ & $18.22 \mathrm{~b}$ & $50.88 \mathrm{~b}$ & $74.88 \mathrm{~b}$ \\
N1B2 & $7.00 \mathrm{~b}$ & $12.55 \mathrm{~b}$ & $18.22 \mathrm{~b}$ & $50.22 \mathrm{~b}$ & $74.11 \mathrm{~b}$ \\
N2B2 & $8.00 \mathrm{c}$ & $14.00 \mathrm{~d}$ & $20.22 \mathrm{~d}$ & $52.33 \mathrm{c}$ & $76.66 \mathrm{c}$ \\
N3B2 & $7.22 \mathrm{~b}$ & $12.55 \mathrm{~b}$ & $18.99 \mathrm{c}$ & $50.33 \mathrm{~b}$ & $73.88 \mathrm{~b}$ \\
N4B2 & $7.10 \mathrm{~b}$ & $12.11 \mathrm{ab}$ & $18.22 \mathrm{~b}$ & $51.55 \mathrm{bc}$ & $74.44 \mathrm{~b}$ \\
N1B3 & $7.22 \mathrm{~b}$ & $13.00 \mathrm{bc}$ & $18.77 \mathrm{bc}$ & $50.22 \mathrm{~b}$ & $74.33 \mathrm{~b}$ \\
N2B3 & $7.44 \mathrm{~b}$ & $12.44 \mathrm{ab}$ & $17.99 \mathrm{~b}$ & $50.77 \mathrm{~b}$ & $75.11 \mathrm{bc}$ \\
N3B3 & $7.11 \mathrm{~b}$ & $12.44 \mathrm{ab}$ & $17.55 \mathrm{~b}$ & $50.88 \mathrm{~b}$ & $74.11 \mathrm{~b}$ \\
N4B3 & $7.33 \mathrm{~b}$ & $12.55 \mathrm{~b}$ & $18.44 \mathrm{bc}$ & $50.77 \mathrm{~b}$ & $74.88 \mathrm{~b}$ \\
\hline
\end{tabular}

Keterangan : Angka-angka yang diikuti dengan huruf yang sama pada kolom yang sama tidak berbeda nyata pada Uji Duncan $(\alpha=0,05)$.

Hasil tertinggi terhadap jumlah daun tanaman cabai merah keriting ditunjukkan pada perlakuan dosis NPK Phonska 0.832 g/ polybag dan Bokashi 41.6 g/ polybag (N2B2) pada semua umur pengamatan dan perlakuan terendah ditunjukkan perlakuan dosis NPK Phonska $0.624 \mathrm{~g} /$ polybag dan Bokashi $20.8 \mathrm{~g} /$ polybag (N1B1) pada semua umur pengamatan. Hal ini di duga interaksi pemberian NPK dan Bokashi saling mendukung dalam memenuhi asupan nutrisi ketanaman sehingga tanaman mampu menyerap unsur hara yang tersedia dengan baik dan proses fotosintesis dapat berjalan lancar di daun tanaman hal tersebut dapat meningkatkan jumlah daun tanaman cabai merah keriting. Daun merupakan bagian tanaman yang digunakan untuk melakukan fotosintesis. Hasil fotosintesis berupa asimilat digunatakan tanaman dalam fase vegetatif dan generative (Murdianingtyas PH et al. 2012). 
Faiftin Nurul Laili, Tri Kurniastuti \& Palupi Puspitorini, 2020. Respon Pertumbuhan dan hasil

Tanaman Cabai Merah Keriting (Capsicum annum Var. Longun L) Terhadap Pemberian Pupuk NPK Dan Bokashi. Journal Viabel Pertanian. (2020), 14(1)37-43

\section{Diameter Batang}

Berdasarkan hasil analisis dari sidik ragam (ANOVA) pada taraf 5\% menunjukkan bahwa terdapat interaksi yang nyata terhadap diameter batang tanaman cabai merah keriting (Capsicum annum Var. Longun L.) pada umur pengamatan 14 HST, 21 HST, 28 HST, 35 HST, 42 HST. Untuk mengetahui perbedaan antara perlakuan yang terbaik terhadap tinggi tanaman dapat di lihat pada tabel di bawah ini :

Tabel 3. Rata Rata Diameter Batang Tanaman Cabai Merah Keriting Pada Umur

Pengamatan 14 HST, 21 HST, 28 HST, 35 HST, 42 HST.

\begin{tabular}{lccccl}
\hline \multirow{2}{*}{ Perlakuan } & \multicolumn{5}{c}{ Diameter Batang $(\mathrm{cm})$} \\
& $14 \mathrm{HST}$ & $21 \mathrm{HST}$ & $28 \mathrm{HST}$ & $35 \mathrm{HST}$ & $49 \mathrm{HST}$ \\
\hline N1B1 & $0.40 \mathrm{a}$ & $0.46 \mathrm{a}$ & $0.56 \mathrm{a}$ & $0.61 \mathrm{a}$ & $0.64 \mathrm{a}$ \\
N2B1 & $0.41 \mathrm{a}$ & $0.52 \mathrm{~b}$ & $0.56 \mathrm{a}$ & $0.71 \mathrm{~b}$ & $0.85 \mathrm{bc}$ \\
N3B1 & $0.42 \mathrm{a}$ & $0.54 \mathrm{~b}$ & $0.62 \mathrm{~b}$ & $0.72 \mathrm{bc}$ & $0.87 \mathrm{c}$ \\
N4B1 & $0.42 \mathrm{a}$ & $0.50 \mathrm{ab}$ & $0.63 \mathrm{~b}$ & $0.72 \mathrm{bc}$ & $0.80 \mathrm{bc}$ \\
N1B2 & $0.41 \mathrm{a}$ & $0.52 \mathrm{~b}$ & $0.63 \mathrm{~b}$ & $0.72 \mathrm{bc}$ & $0.85 \mathrm{bc}$ \\
N2B2 & $0.50 \mathrm{~b}$ & $0.61 \mathrm{c}$ & $0.70 \mathrm{c}$ & $0.80 \mathrm{~d}$ & $0.90 \mathrm{c}$ \\
N3B2 & $0.41 \mathrm{a}$ & $0.51 \mathrm{ab}$ & $0.63 \mathrm{~b}$ & $0.71 \mathrm{~b}$ & $0.86 \mathrm{c}$ \\
N4B2 & $0.41 \mathrm{a}$ & $0.53 \mathrm{~b}$ & $0.61 \mathrm{ab}$ & $0.73 \mathrm{c}$ & $0.80 \mathrm{~b}$ \\
N1B3 & $0.40 \mathrm{a}$ & $0.57 \mathrm{bc}$ & $0.64 \mathrm{bc}$ & $0.72 \mathrm{bc}$ & $0.87 \mathrm{c}$ \\
N2B3 & $0.40 \mathrm{a}$ & $0.48 \mathrm{ab}$ & $0.57 \mathrm{ab}$ & $0.63 \mathrm{a}$ & $0.66 \mathrm{a}$ \\
N3B3 & $0.40 \mathrm{a}$ & $0.54 \mathrm{~b}$ & $0.61 \mathrm{ab}$ & $0.72 \mathrm{bc}$ & $0.83 \mathrm{bc}$ \\
N4B3 & $0.40 \mathrm{a}$ & $0.52 \mathrm{~b}$ & $0.63 \mathrm{~b}$ & $0.72 \mathrm{bc}$ & $0.85 \mathrm{bc}$ \\
\hline
\end{tabular}

Keterangan : Angka-angka yang diikuti dengan huruf yang sama pada kolom yang sama tidak berbeda nyata pada uji Duncan $(\alpha=0,05)$.

Hasil tertinggi terhadap diameter batang tanaman cabai merah keriting ditunjukkan pada perlakuan dosis NPK Phonska 0.832 g/ polybag dan Bokashi 41.6 g/ polybag (N2B2) pada semua umur pengamatan dan perlakuan terendah ditunjukkan perlakuan dosis NPK Phonska $0.624 \mathrm{~g} /$ polybag dan Bokashi $20.8 \mathrm{~g} /$ polybag (N1B1) pada semua umur pengamatan. Hal ini di duga dengan pengaplikasian NPK sebesar $0.832 \mathrm{~g} /$ polybag dan pengaplikasian pupuk organik bokhasi 41.6 gram/polybag mampu sebagai tambahan unsur hara yang di berikan pada tanaman. Penambahan unsur hara pada tanaman membantu penyerapan nutrisi tanaman karena ketersediaan hara yang tinggi sehingga tanaman mudah untuk mendapatkan nutrisi untuk memenuhi kebutuhan tanaman, ketersediaan hara yang tinggi memungkinkan penyerapan hara yang tinggi oleh tanaman (Supriyadi et al. 2014).

\section{Jumlah Buah}

Berdasarkan hasil analisis dari sidik ragam (ANOVA) pada taraf 5\% menunjukkan bahwa terdapat interaksi yang nyata terhadap jumlah buah total tanaman cabai merah keriting (Capsicum annum var. LongunL. )pada umur pengamatan panen ke 1 sampai panen ke 5. Untuk mengetahui perbedaan antara perlakuan yang terbaik terhadap tinggi tanaman dapat di lihat pada tabel di bawah ini : 
Faiftin Nurul Laili, Tri Kurniastuti \& Palupi Puspitorini, 2020. Respon Pertumbuhan dan hasil Tanaman Cabai Merah Keriting (Capsicum annum Var. Longun L) Terhadap Pemberian Pupuk NPK Dan Bokashi. Journal Viabel Pertanian. (2020), 14(1)37-43

Tabel 4. Total Jumlah Buah Tanaman Cabai Merah Keriting Pada Pengamatan Panen ke 1 Sampai Panen ke 5

\begin{tabular}{cc}
\hline Perlakuan & jumlah buah total \\
\hline N1B1 & $31.22 \mathrm{a}$ \\
N2B1 & $44.66 \mathrm{~d}$ \\
N3B1 & $46.55 \mathrm{e}$ \\
N4B1 & $42.65 \mathrm{c}$ \\
N1B2 & $41.52 \mathrm{~b}$ \\
N2B2 & $52.22 \mathrm{f}$ \\
N3B2 & $46.65 \mathrm{e}$ \\
N4B2 & $44.78 \mathrm{~d}$ \\
N1B3 & $43.44 \mathrm{c}$ \\
N2B3 & $45.54 \mathrm{de}$ \\
N3B3 & $44.44 \mathrm{~d}$ \\
N4B3 & $44.44 \mathrm{~d}$ \\
\hline
\end{tabular}

Keterangan : Angka-angka yang diikuti dengan huruf yang sama pada kolom yang sama tidak berbeda nyata pada uji Duncan $(\alpha=0,05)$.

Hasil tertinggi terhadap jumlah buah total tanaman cabai merah keriting ditunjukkan pada perlakuan dosis NPK Phonska $0.832 \mathrm{~g} /$ polybag dan Bokashi $41.6 \mathrm{~g} /$ polybag (N2B2) dengan total jumlah daun 52.22 buah dan perlakuan terendah ditunjukkan perlakuan dosis NPK Phonska $0.624 \mathrm{~g} /$ polybag dan Bokashi $20.8 \mathrm{~g} /$ polybag (N1B1) dengan total jumlah daun 31.22 buah. Hal ini dikarenakan pemberian hara yang dilakukan mampu diserap dengan optimal oleh tanaman untuk dapat membentuk umbi terutama hara K. Kalium dapat meningkatkan hasil suatu tanaman dalam hal ini buah tanaman cabai merah keriting (Helal Nas, AbdElhadySA. 2015). Sejalan yang di kemukakan Aminifard, et al. (2010) tanaman sayuran termasuk cabai hasil respon terhadap kalium sangat penting bagi tanaman. Penggunaan terlalu banyak dan sedikit pupuk K akan mengakibatkan turunnya kuantitas tanaman.

\section{Bobot Buah}

Berdasarkan hasil analisis dari sidik ragam (ANOVA) pada taraf 5\% menunjukkan bahwa terdapat interaksi yang nyata terhadap bobot buah total tanaman cabai merah keriting pada umur pengamatan panen ke 1 sampai panen ke 5. Untuk mengetahui perbedaan antara perlakuan yang terbaik terhadap tinggi tanaman dapat di lihat pada tabel di bawah ini : 
p-ISSN: 1978-5259 e-ISSN: 2527-3345

Copyright@UNISBA Blitar, http://ejournal.unisbablitar.ac.id/index.php/viabel

Faiftin Nurul Laili, Tri Kurniastuti \& Palupi Puspitorini, 2020. Respon Pertumbuhan dan hasil

Tanaman Cabai Merah Keriting (Capsicum annum Var. Longun L) Terhadap Pemberian Pupuk NPK Dan Bokashi. Journal Viabel Pertanian. (2020), 14(1)37-43

Tabel 5. Bobot Buah Total Tanaman Cabai Merah Keriting Pada Pengamatan Panen ke 1 Sampai Panen ke 5

\begin{tabular}{cc}
\hline Perlakuan & Bobot Buah Total \\
\hline N1B1 & $118.87 \mathrm{a}$ \\
N2B1 & $195.87 \mathrm{bc}$ \\
N3B1 & $206.65 \mathrm{c}$ \\
N4B1 & $195.09 \mathrm{c}$ \\
N1B2 & $189.65 \mathrm{~b}$ \\
N2B2 & $244.54 \mathrm{~d}$ \\
N3B2 & $207.55 \mathrm{c}$ \\
N4B2 & $200.65 \mathrm{bc}$ \\
N1B3 & $195.87 \mathrm{bc}$ \\
N3B3 & $208.09 \mathrm{c}$ \\
N4B3 & $201.21 \mathrm{bc}$ \\
\hline
\end{tabular}

Keterangan: Angka-angka yang diikuti dengan huruf yang sama pada kolom yang sama tidak berbeda nyata pada uji Duncan $(\alpha=0,05)$.

Hasil tertinggi terhadap total jumlah buah tanaman cabai merah keriting ditunjukkan pada perlakuan dosis NPK Phonska $0.832 \mathrm{~g} /$ polybag dan Bokashi $41.6 \mathrm{~g} /$ polybag (N2B2) dengan bobot buah total 244.54 gramdan perlakuan terendah ditunjukkan perlakuan dosis NPK Phonska 0.624 g/ polybag dan Bokashi 20.8 g/ polybag (N1B1) dengan bobot buah total 118.87 gram. Hal ini di duga pupuk NPK memiliki peran yang baik bagi bobot tanaman kareana masing-masing unsur NPK memiliki fungsi untuk meningkatkan bobot buah tanaman. Unsur $\mathrm{N}, \mathrm{P}$, dan $\mathrm{K}$ mendorong pertumbuhan dan meningkatkan produksi biomasa dan pemupukan $\mathrm{N}, \mathrm{P}$, dan $\mathrm{K}$ digunakan untuk meningkatkan produksi dan hasil tanaman (Aminifard, et al. 2010).

\section{KESIMPULAN}

Berdasarkan hasil penelitian mengenai respon pertumbuhan dan hasil tanaman caba imerah keriting (capsicum annum var. Longun L.) terhadap pemberian dosis pupuk NPK dan bokashi disimpulkan sebagai berikut : Terdapat interaksi antara pemberian dosis pupuk NPK dan pupuk bokashi terhadap pertumbuhan tinggi tanaman, jumlah daun, diameter batang pada semua umur pengamatan dan hasil jumlah buah total, bobot buah total tanaman cabai merah keriting. Kombinasi terbaik untuk pertumbuhan dan hasil yaitu pada perlakuan dosis NPK Phonska $0.832 \mathrm{~g} /$ polybag dan Bokashi $41.6 \mathrm{~g} /$ polybag (N2B2).

\section{DAFTAR PUSTAKA}

Aminifard, MH, Hossein, A, Hamide, I, Atefea \& Sajede, K 2010, 'Responses of eggplant to different rates of nitrogen under field conditions', J. of Central.Euro.Agrice, 11 (4):8-453.

Hapsoh, Gusmawartati, Amri. A. I., dan Diansyah. A . 2017. Respons Pertumbuhan dan Produksi Tanaman Cabai Keriting (Capsicum annuum L.) terhadap Aplikasi Pupuk Kompos dan Pupuk Anorganik di Polibag. J. Hort. Indonesia 8(3): 203-208.

Helal Nas, Abd Elhady SA. 2015. Calcium and potassium Fertilizatin may enhance potato yield and quality. J Agriculture. 4(4):991-998.

Hulopi,. 2006. Pengaruh pemberian bokashi dan NPK terhadap pertumbuhan dan produksi tanaman tomat. Skripsi. Pekanbaru: UIR. Hal 43. 
Faiftin Nurul Laili, Tri Kurniastuti \& Palupi Puspitorini, 2020. Respon Pertumbuhan dan hasil

Tanaman Cabai Merah Keriting (Capsicum annum Var. Longun L) Terhadap Pemberian Pupuk NPK Dan Bokashi. Journal Viabel Pertanian. (2020), 14(1)37-43

Muchyar. 2005. Pertumbuhan dan Hasil Cabai Rawit (Capsicum frutescents) Pada Pemberian Beberapa Dosis Dalam Jenis Bokashi Gulma Air Di Tanah Ultisol. Tesis Program Studi Agronomi Pascasarjana Agronomi, Unlam, Banjarbaru. Hal 12.

Murdianingtyas PH, Indradewa D, Gunadi N. 2012. Pengaruh pengurangan daun terhadap pertumbuhan dan hasil dua varietas paprika (Capsicum annumvar. Grossum) hidroponik. J Vegetalika. 1(3):1-9.

Musnamar, E. I. 2003. Pupuk Organik. Penebar Swadaya. Jakarta. Nur, M. 2005. Pengaruh Dosis Bokasi Jerami Padi dan Pemberian EM-4 terhadap pertumbuhan dan Hasil Kedelai (Glycine max L) Varietas Tampomas. Skripsi. Badan Perencanaan Pembangunan Daerah provinsi Nanggroe Aceh Darussalam. Aceh.55 hal.

Silvia, M., Susanti, H.,Samharinto dan Gt. M. Sugian Noor.2016. Produksi Tanaman Cabe Rawit (Capsicum Frutescent L.) Di Tanah Ultisol Menggunakan Bokashi Sampah Organik Rumah Tangga Dan Npk. 12(1) :22-27.

Supriyadi, Sri H., dan Almar A.2014. Kajian Pemberian Pupuk P, Pupuk Mikro dan Pupuk Organik terhadap Serapan P dan Hasil Kedelai (Glycine Max L.) Varietas Kaba di Inseptisol Gunung Gajah Klaten. Program Studi Ilmu Tanah, Fakultas Pertanian Universitas Sebelas Maret Surakarta. Jurnal Ilmu-Ilmu Pertanian29 (2):81-86.

Waskito, H., A. Nuraini., N. Rostini. 2018. Respon pertumbuhan dan hasil cabai keriting (Capsicum annuum L.) Ck5 akibat perlakuan pupuk NPK dan pupuk hayati. Jurnal Kultivasi Vol. 17 (2) . 